\title{
PROVIDING LINK-16 ON DISADVANTAGED PLATFORMS USING THE MULTI-ROLE ADVANCED TRANSCEIVER
}

\author{
Robert L. Riley, Jr., Air Force Research Laboratory, Munitions Directorate, Eglin AFB, FL
}

\begin{abstract}
Link-16 is a secure, anti-jam communications protocol that has been fielded extensively throughout the US and NATO Armed services for aircraft, ground elements and maritime vessels. This paper highlights the Link-16 demonstration results of the Multi-role Advanced Transceiver (MAX) terminal during the Navy's Trident Warrior 2007 exercise. The MAX terminal is a small form-factor, software-defined radio capable of implementing UHF line-of-sight, UHF satellite communications, or Link-16 interchangeably over a single channel. The results of the Trident Warrior 2007 demonstration show that the MAX terminal offers an unprecedented level of visual situational awareness for enhanced tracking and targeting via Link-16 for disadvantaged platforms.
\end{abstract}

\section{Introduction}

For the last 13 years, Link-16 has been employed under the designation of primary tactical data link (TDL) for the Department of Defense (DoD) which includes all U.S. military service and defense agency command, control communications, computers, intelligence, surveillance, and reconnaissance ( $\mathrm{C}^{4} \mathrm{ISR}$ ) assets [1]. With that being the case, it is no surprise that the majority of the larger maritime, airborne and ground/fixed platforms across DoD have been Link-16 capable for more than a decade now. A part of the reason for this is because these platforms view the JTIDS/MIDS terminal footprint as nominal at best. Unfortunately, with the smallest Multi-functional Information Distribution System Low Volume Terminal (MIDS LVT) weighing in at a max of 55 lbs and 800 in. $^{3}$ in size, the cost, size, weight and power (CSWAP) constraints are a lot more problematic when considering rotary-wing aircraft, small boats, ground vehicles and dismounted troops. Figure 1 shows the MIDS LVT 3 Fighter Data Link (FDL), which is the smallest MIDS terminal available [2].

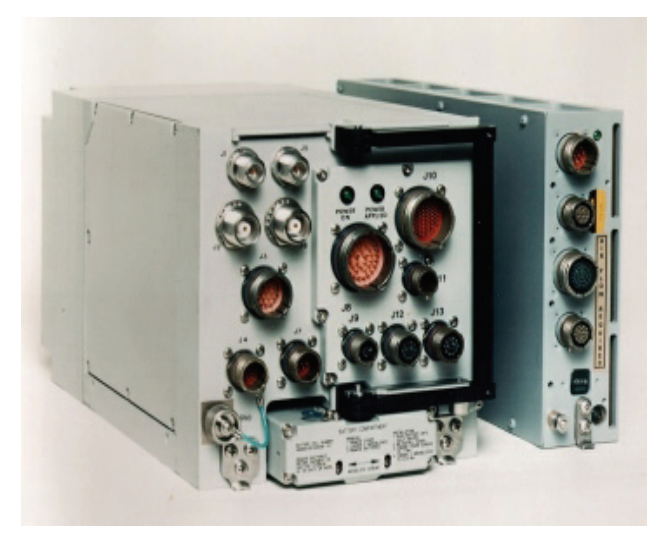

Figure 1. MIDS LVT 3 (FDL)

Such constraints can be a major impediment when it comes to installing advanced technology that can enhance the ability of these platforms to accomplish their missions (i.e. infiltration, combat search and rescue, anti-surface warfare). These disadvantaged platforms are heavily used by certain DoD communities including Special Operations and Tactical Air Control Parties (TACP). Such platforms have been previously restricted to primarily using voice communications for coordination of tactical military operations. Although Link-16 is a high-capacity, jam-resistant and secure TDL $[1,3,4]$, it has not been reduced to smaller form factors until very recently.

Another consideration is the need for flexibility in utilizing various communication protocols on the same system. The Joint Tactical Radio System (JTRS) program was established by the DoD to address this issue of interoperability in order to improve robustness in airborne networking [3] and to further enable current terrestrial and satellite communications. In lieu of the JTRS radios that will be procured, there are current warfighter needs that can be met with intermediate technologies such as the MAX terminal. 


\section{Description of the MAX Terminal}

The MAX terminal is the brassboard prototype that was produced under the Air Force's Common Weapon Data Link Advanced Technology Demonstration (ATD) program. This $\$ 11 \mathrm{M}$ effort was jointly funded by the Air Force Research Laboratory's Information (IF) and Munition (MN) Directorates. The initial intent of the program was to address an Air Force warfighter requirement that called for conventional weapon systems to host a 2way data link capability that would enable weapon control handoff, target abort/re-direct, and the transmission of pre-impact bomb damage information (BDI) directly from the weapon. This requirement was in direct support of a consolidated effort by DoD to execute network-centric operations for current and future military engagements in the U.S and overseas.

The current MAX terminal is $5 \mathrm{lbs}$ in weight, 79 in. $^{3}$ in size, and capable of hosting three software defined radio waveforms over a single channel: UHF FM FSK line-of-sight (LOS), UHF $5 \mathrm{kHz}$ SATCOM demand assigned single access (DASA), and Link-16 (MIL-STD-6016C) [5]. It hosts a wideband power amplifier that spans from $225 \mathrm{MHz}$ to $2 \mathrm{GHz}$ with a nominal power output of 25 watts. As a result of interest from the user community, Link-16 is the only waveform that has been fieldtested and the current test fixture has been designed to directly support this TDL. For field demonstrations, NAVAIR has retrofitted a Pelican Case 1620 to serve as the test fixture that is used to house all of the necessary peripherals needed for testing (i.e. GPS receiver, laptop, batteries, DS-102 crypto port). Figure 2 shows a picture of the MAX terminal.

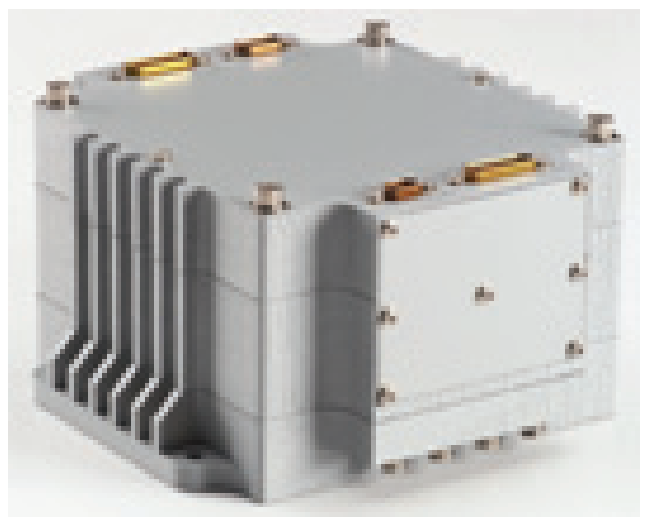

Figure 2. MAX Terminal
Figure 3 shows the MAX terminal mounted in its Pelican Case. Along with the terminal, there is a Rockwell-Collins Defense Advanced GPS Receiver (DAGR) mounted along side cabled wires and shock-hardened connectors. The interior lid serves as the spool storage area for the various cables (i.e. power, L-band antenna, GPS, RS-232, VGA) that are used to run the MAX test fixture.

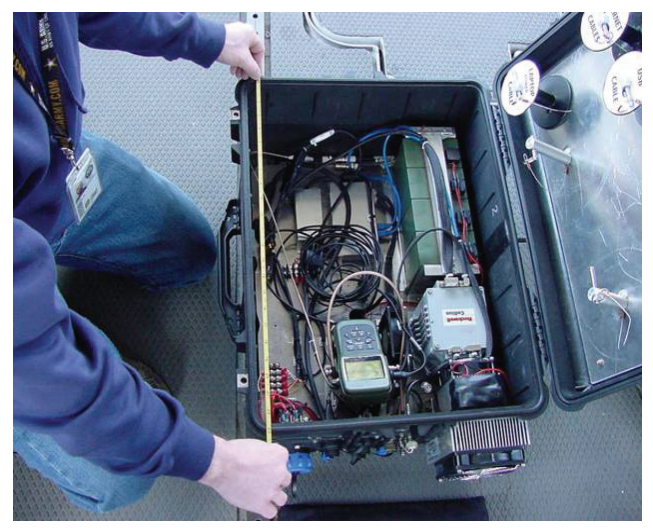

Figure 3. MAX in Pelican Case

The terminal is currently controlled via a RS232 connection to a Panasonic Toughbook laptop which hosts the Rockwell-Collins software application that is responsible for processing the Link-16 messages. Those messages are then displayed across the FalconView mapping software application [6]. A third piece of software, a tactical GUI, has been designed to lie across the FalconView map. Once the system has entered course sync in a Link-16 network, The GUI displays all the various track reports, precise position location information (PPLI), as well as course and bearing information with respect to the GPS timing signal. Figure 4 shows the FalconView display. 


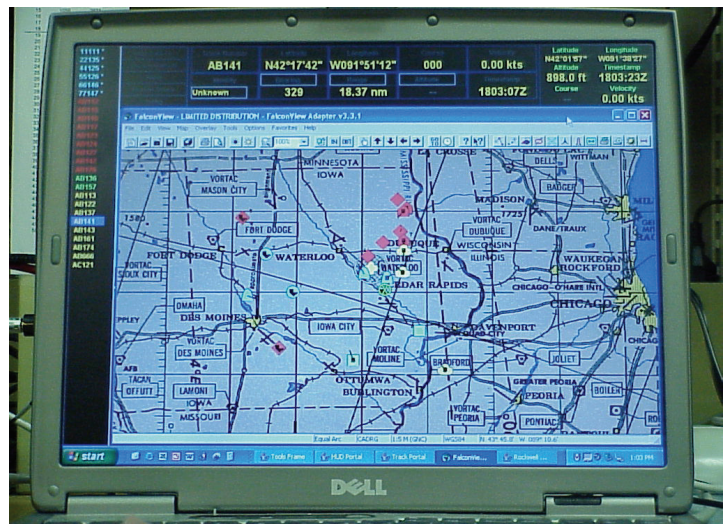

Figure 4. NAVAIR GUI over FalconView Screenshot

With respect to other platforms associated with a Link-16 network design load (NDL), the MAX terminal has been configured to act as an F15E. As a fighter platform, one would not expect the associated time slot duty factor (TSDF) to be high. As such, the MAX terminal aligns its TSDF with that of the standard F-15E platform which falls in the area of $4.3 \%$. Modified platform loads were previously developed by the Air Force JTIDS/MIDS Network Design Facility (AF NDF) to allow for the transmittal of free-text messages (J28.2), surveillance track report messages (J3.X) and other messages related to fires engagement, weapon control and battle damage assessment (i.e. $\mathrm{J} 12.0)$. According to the AF NDF, this only increased the TSDF for the MAX platform load to $6.98 \%$, still well within the range of being considered nominal $(<20 \%)$ for intended use during Link-16 test or demonstration [7].

The MAX terminal is capable of using several types of UHF antennas which include the Link-16 frequency band $(960-1215 \mathrm{MHz})$ which is reserved on a worldwide basis for the safe operation of aeronautical radio navigation equipment [8]. A variety of various GPS antennas have been utilized for field testing in order to capture the GPS signal for timing synchronization of the MAX terminal in the various Link-16 networks that it has operated in. Due to the experimental nature of this terminal, coordination with the Navy \& Marine Corps Spectrum Center (NMSC) has been ongoing with the ultimate intent of securing temporary authorization to transmit Link-16 data over-the-air using the MAX terminal. NMSC is the DoD Link16 Controlling Authority and has been charged with the responsibility of working with the Federal Aviation Administration (FAA) to coordinate all DoD use of Link-16 [7]. As such, the development of a Request for Deviation (RfD) is currently under way and will be submitted to NMSC/FAA for approval which, in turn, would allow for the authorized transmittal of Link-16 data over-the-air using the MAX terminal [8].

With regards to cryptographic support, KYK13 cryptographic key loaders have been successfully used to load Link-16 cryptographic test keys into the MAX terminals. The terminals utilize an initial version of Rockwell-Collins's JANUS cryptographic processing engine. It should be noted that the MAX terminal is only authorized to use cryptographic test keys for support of Link-16 activities. This is due to the fact that the onboard cryptographic engine is based around a fieldprogrammable gate array (FPGA) chipset, which is deemed by NSA to be an unsecured processing platform for supporting anything more than cryptographic test keys. As a result, regular waivers to use Link-16 cryptographic test keys for test and demonstration of the MAX terminals have been secured from NSA.

\section{Background on Trident Warrior}

Trident Warrior 2007 is an annual Navy Network Warfare Command (NAVNETWARCOM) exercise that has been successfully used for demonstrating the functionality of innovative communication systems, secure information management applications and new network-centric technologies [9]. It is designed to create an operational environment in which innovative technologies in the areas of command and control $\left(\mathrm{C}^{2}\right)$, information operations, knowledge management, networks, maritime domain awareness, and fire control can be demonstrated. These technologies are demonstrated in relevant scenarios and are assessed by observers for any military utility that they may offer the warfighter.

The Link-16 capability offered by the MAX terminal was demonstrated during Trident Warrior 2007. The MAX terminal was coordinated for demonstration as a Fires Support technology that would aid disadvantaged users. The MAX terminal was placed onboard the STILETTO, an experimental, high-speed watercraft sponsored by 
the Office of the Secretary of Defense (OSD) for use by the US Special Operations Command (USSOCOM). These platforms and others (i.e. forward observers, helicopters) represent systems that have traditionally been subject to CSWAP constraints and are thus referred to as "disadvantaged platforms".

\section{MAX Exercise Plan and Objectives}

Under the Fires Working Group of Trident Warrior 2007, the MAX Link-16 effort was slated to involve several Link-16 participants, yet the objectives of the Fires Working Group Link-16 demonstration were heavily centered on the MAX terminal. Those objectives were to 1) demonstrate the military utility of the Link-16 situational awareness picture provided by MAX, 2) demonstrate the military utility of Link-16 interoperability between traditional and disadvantaged platforms, and 3) demonstrate the ability of MAX to effectively operate in a Link-16 network in support of a Joint Fires Engagement.

For the Link-16 demonstration, an E-3 Airborne Warning and Control System (AWACS) was chosen to serve as the airborne intelligence, surveillance and reconnaissance (ISR) platform as well as the network time reference (NTR). The AWACs was operated by the $552^{\text {nd }}$ Air Control Wing's Operations Support Squadron (OSS) which is based out of Tinker Air Force Base in Oklahoma.

A new Link-16 capability was to be demonstrated as a part of the Navy's P-3C AntiSurface Warfare Improvement Program (AIP) [10] which was also under the Fires Working Group. Thus, the P-3C was chosen to serve as the $\mathrm{C}^{2}$ platform responsible for maritime target designation during the demonstration. The P-3C was operated by NAVAIR 5.1.2.4 and VX-20, both subordinate units of the Naval Air Systems Command (NAVAIRSYSCOM) based out of Naval Air Station, Patuxent River, Maryland.

The USS Harry S Truman (CVN-21), a Navy aircraft carrier, was scheduled to support demonstration of various technologies during Trident Warrior 2007 under the direction of Carrier Strike Group Ten (CCSG-10). It was scheduled to participate in the network to facilitate other Link-16 activities for Navy vessels during the exercise.
The Navy HH-60H helicopter was designated to serve as an airborne host platform for the MAX terminal. This rotary-wing aircraft was owned by Carrier Air Wing Three (CVW-3) who serves as a subordinate unit under CCSG-10. CVW-3 is based out of Naval Station Norfolk along with CCSG-10.

The maritime host platform for demonstration of the MAX terminal was the STILETTO watercraft. STILETTO is a twin M-shaped hull, high-speed watercraft that was developed under the direction of the Office for Force Transformation (OFT) which is subordinate to the Office of the Secretary of Defense (OSD). STILETTO was created as an experimental test bed that could be used for demonstration of technologies that support maritime operations, with particular interest in supporting underway activities for the US Special Operations Command (USSOCOM) [11]. Figure 5 shows a picture of STILETTO.

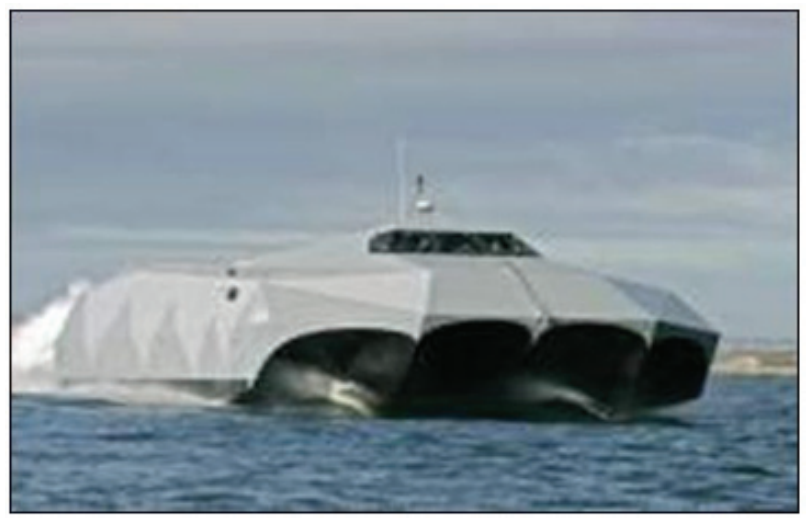

Figure 5. STILETTO

Figure 6 shows the original OV-1 that was developed with the complete Joint Fires Engagement scenario in mind. The concept of operation for the Link-16 exercise was to have the AWACS provide the airborne sensor picture while serving as the ISR platform. The STILETTO would be responsible for providing sea-level target designation via Link-16. Target information would then be passed up to the P-3C for mission assignment of the designated 'hostile' vessel. The P-3C would then task the HH-60H to attack the target. The HH- $60 \mathrm{H}$ would then confirm the kill of the target by transmitting a 'target destroyed' bomb damage assessment message (J12.6) to the network. This scenario was the initial approach to enacting a full-up joint tactical targeting scenario. 


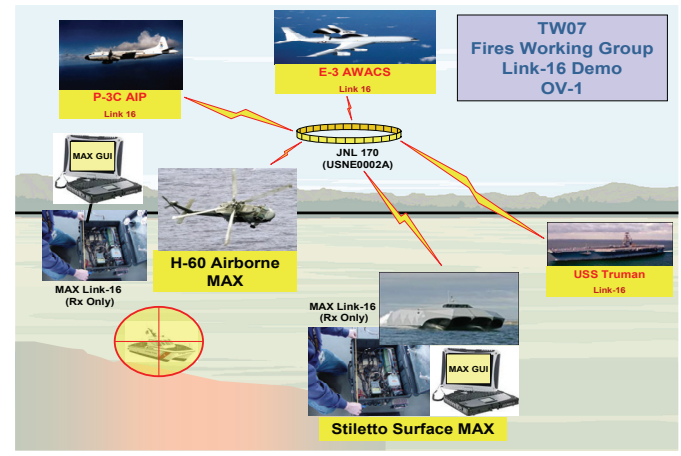

Figure 6. Fires Link-16 OV-1

\section{TW07 MAX Link-16 Coordination}

Before testing could take place, authorization to utilize necessary resources for the demonstration had to be coordinated. This included securing approval from National Security Agency (NSA) to use cryptographic test keys on the MAX terminal, developing a System Security Authorization Agreement (SSAA) [12] to gain approval to operate the MAX terminal onboard STILETTO, and working through NAVAIR to obtain a flight clearance to operate the MAX terminal onboard an H-60 helicopter. All of these approvals were successfully obtained in order to support the exercise. The USNE0002A (JNL 170) Link-16 exercise network load was developed specifically for Trident Warrior 2007 by the Navy Network Design Facility. All operations of the terminal during the Trident Warrior 2007 exercise were conducted in a Receive-only mode where transmitter functionality on the MAX terminal was completely disabled. This mode of operation allowed MAX to operate as a pure SA display terminal.

\section{TW07 MAX Tests and Demonstration}

Preliminary tests were conducted at Naval Air Station Patuxent River with a Navy helicopter asset and then at a later date with the P-3C. These preliminary test events were employed as prudent risk reduction measures in preparation for the Link16 exercise. However, neither the $\mathrm{P}-3 \mathrm{C}$ nor the $\mathrm{HH}-$ $60 \mathrm{H}$ platforms were on hand to participate in the Link-16 demonstration as a result of maintenance problems that affected their availability. Although this impacted the fidelity of the network by removing two active participants, it did not impede the execution of the demonstration or the ability of MAX to meet its objectives.

The MAX Link-16 demonstration took place across two days. On both days, the intended AWACS was used to provide the airborne sensor picture for the network. Test coordination was executed from the Norfolk Operations Center controlled by the Naval Center for Tactical Systems Interoperability Detachment Two (NCTSI Det 2) on Naval Station Norfolk. To begin the exercise, the AWACS was directed to pass free-text/chat messages (J28.2) to the MAX terminal onboard STILETTO to demonstrate this capability and how it could be used to coordinate activity over the network. The MAX operators onboard STILETTO confirmed receipt of all intended messages using UHF voice communications. The AWACS was then responsible for designating both aircraft (J3.2) and maritime surface vessels (J3.3) as either 'unknown', 'friendly', or 'hostile'. This level of target designation was coordinated in order to enact a joint fires engagement where a USAF $\mathrm{C}^{2}$ airborne platform provides tasking for a maritime interdiction operation with STILETTO serving as a USN maritime attack vessel. With STILETTO operating as a 'radio-silent' combatant watercraft, the MAX terminal displayed useful track and target information (i.e. course, bearing, GPS time). The flexibility of STILETTO allowed for routing of the Link-16 SA picture from the laptop to the bridge of the vessel using standard VGA cable. An enactment of an approach on one of the 'hostile' targets that had been previously designated by the AWACS was successfully accomplished.

Near the close of the exercise, the MAX terminal was able to meet a real-time need that had arisen for some of the Navy operators onboard STILETTO. As a result of the dense population of maritime vessels supporting the Trident Warrior 2007 exercise, it was hard to locate any one particular vessel without a supporting $\mathrm{C}^{4} \mathrm{I}$ system. With no other technology available to meet the immediate need, the Link-16 SA picture from MAX was able to aid in locating the 'friendly' vessel (USS Oscar Austin) that was scheduled to support one of the other technologies onboard STILETTO during the Link-16 exercise. After the AWACS located the vessel, they forwarded its position and location as a 'friendly' track which MAX displayed 
on the bridge of STILETTO to allow the operators to vector the vessel. As a result, the operators of the Naval Coastal Warfare Squadron Four (NCWS4) were successfully able to locate and rendezvous with the USS Oscar Austin in time to support their scheduled exercise.

\section{TW07 MAX Test Results}

Due to the nature of the information exchanged across Link-16 during the TW07 demonstration, only a subset of the data has been reported for evaluation. The following three tables show a list of the various messages that were received by the MAX terminal from specific platforms during preliminary test and across the days of actual demonstration. The exact content of these messages has been omitted for security purposes.

Table 1 shows the results of the preliminary test of the MAX terminal with the P-3C and NAVAIR's Surface Aviation Interoperability Laboratory (SAIL) which took place at Naval Air Station Patuxent River. The SAIL acted as a maritime vessel for this particular test which explains its broadcasted designation in the table as a surface PPLI (J2.3). SAIL used their TADIL-J Host Simulator (TJHS) [13] to inject J-series messages into the Link-16 network.

Table 1. Messages Received by MAX during Preliminary Test

\begin{tabular}{|c|c|c|}
\hline $\begin{array}{c}\text { J-SERIES } \\
\text { SET }\end{array}$ & \multicolumn{2}{|c|}{$\begin{array}{c}\text { TRANSMIT } \\
\text { PLATFORM }\end{array}$} \\
\hline & P-3C & SAIL \\
\hline $\mathrm{J} 0.0$ & $\mathrm{X}$ & $\mathrm{X}$ \\
\hline $\mathrm{J} 0.7$ & & $\mathrm{X}$ \\
\hline $\mathrm{J} 2.2$ & $\mathrm{X}$ & \\
\hline $\mathrm{J} 2.3$ & & $\mathrm{X}$ \\
\hline $\mathrm{J} 3.2$ & & $\mathrm{X}$ \\
\hline $\mathrm{J} 3.3$ & $\mathrm{X}$ & $\mathrm{X}$ \\
\hline $\mathrm{J} 3.4$ & & $\mathrm{X}$ \\
\hline $\mathrm{J} 13.2$ & $\mathrm{X}$ & \\
\hline $\mathrm{J} 13.3$ & & $\mathrm{X}$ \\
\hline $\mathrm{J} 31.7$ & $\mathrm{X}$ & $\mathrm{X}$ \\
\hline
\end{tabular}

Table 2 shows the results of the first day of live test for the TW07 exercise. As mentioned previously, this testing occurred off the coast of Naval Station Norfolk and involved only the airborne AWACS and the MAX terminal onboard STILETTO while it was underway. The key message that was demonstrated on this day of live test was the ability of the MAX terminal to receive and process the free-text/chat message (J28.2) as well as the $\mathrm{J} 7$.X series messages for track management (J7.0) and track identification (J7.4).

Table 2. Messages Received by MAX during TW07 (Day 1)

\begin{tabular}{|c|c|}
\hline $\begin{array}{c}\text { J-SERIES } \\
\text { SET }\end{array}$ & $\begin{array}{c}\text { TRANSMIT } \\
\text { PLATFORM }\end{array}$ \\
\hline & AWACS (E3) \\
\hline J0.0 & $\mathrm{X}$ \\
\hline $\mathrm{J} 2.2$ & $\mathrm{X}$ \\
\hline $\mathrm{J} 3.2$ & $\mathrm{X}$ \\
\hline $\mathrm{J} 3.3$ & $\mathrm{X}$ \\
\hline $\mathrm{J} 3.4$ & $\mathrm{X}$ \\
\hline $\mathrm{J} 3.5$ & $\mathrm{X}$ \\
\hline $\mathrm{J} 7.0$ & $\mathrm{X}$ \\
\hline $\mathrm{J} 7.4$ & $\mathrm{X}$ \\
\hline $\mathrm{J} 13.2$ & $\mathrm{X}$ \\
\hline $\mathrm{J} 28.2$ & $\mathrm{X}$ \\
\hline $\mathrm{J} 31.7$ & \\
\hline
\end{tabular}

Table 3 shows the results of the second day of live test for the TW07 exercise. The test configuration on both days was nearly identical since there were no additional Link-16 platforms that entered the network. The demonstration on this day concluded the MAX terminal testing. 
Table 3. Messages Received by MAX during TW07 (Day 2)

\begin{tabular}{|c|c|}
\hline $\begin{array}{c}\text { J-SERIES } \\
\text { SET }\end{array}$ & $\begin{array}{c}\text { TRANSMIT } \\
\text { PLATFORM }\end{array}$ \\
\hline & AWACS (E3) \\
\hline $\mathrm{J} 0.0$ & $\mathrm{X}$ \\
\hline $\mathrm{J} 2.2$ & $\mathrm{X}$ \\
\hline $\mathrm{J} 3.2$ & $\mathrm{X}$ \\
\hline $\mathrm{J} 3.3$ & $\mathrm{X}$ \\
\hline $\mathrm{J} 3.4$ & $\mathrm{X}$ \\
\hline $\mathrm{J} 3.5$ & $\mathrm{X}$ \\
\hline $\mathrm{J} 7.0$ & \\
\hline $\mathrm{J} 7.4$ & $\mathrm{X}$ \\
\hline $\mathrm{J} 13.2$ & $\mathrm{X}$ \\
\hline $\mathrm{J} 28.2$ & \\
\hline $\mathrm{J} 31.7$ & $\mathrm{X}$ \\
\hline
\end{tabular}

In general, these results were highly favorable being that the J-series messages that were received by the MAX terminal correlated well with what was transmitted by the three Link-16 platforms. This was confirmed using UHF voice coordination during the test activities as well as by visual inspection in the case of the SAIL facility. This actually touches on one area of improvement that was noted during the post-mission analysis phase of this exercise. For future demonstrations, it is desired that all Link-16 participants have the ability to record the J-series message traffic of the intended network. This would offer the option of performing post-mission analysis with a much higher level of fidelity (i.e. bit-level comparisons).

\section{TW07 MAX Survey and Observation Results}

For the TW07 live tests, there was a survey as well as an observation log that was created to help operators assess the military utility of the Link-16 SA picture that was provided by the MAX terminal.

With regards to system advantages, several of the surveyed participants and observers felt that the Link-16 tracks over the FalconView maps provided a significant increase in visual understanding of the surrounding maritime environment. Most felt that the icons were easily readable and that color-coding of the track numbers helped to interpret their meanings. One of the operators expressed that "it was a lot easier to use GPS coordinates while being able to see what was going on." Overall observations suggested that the MAX terminal continuously remained stable in the network once it reached course sync. Positive comments were made regarding the compact design of the MAX terminal.

With regards to the disadvantages of the system, some felt that the standard set of Navy or DoD (i.e. MIL-STD-2525) symbols would be better than what was used in FalconView. Also, the operators expressed an interest in seeing the MAX terminal access $\mathrm{C}^{2}$ data via GCCS-M for a more robust SA picture. These were the extent of the disadvantages as expressed by the observers.

\section{Future Efforts}

Overall, the demonstrations of the MAX terminal to date have been very promising. With regards to meeting the current needs of warfighters, it offers a very strong capability that disadvantaged platforms have not had access to. The Navy remains very interested in the technology. As a result, there are plans currently under way to participate in the Trident Warrior 2008 with the hope of demonstrating the full transceiver capability of the MAX terminal while in a Link-16 network. Also, airborne demonstration of the MAX terminal onboard a rotary-wing aircraft would be pursued with a more probable chance of success.

The successor of the Common Weapon Data Link program, the DARPA QUINT Networking Technology (QNT) program, will bring IP-based networking capability into a small form-factor in order to better support disadvantaged platforms. These data links will enable precision targeting and engagement against both time-critical and mobile targets. This will include the Tactical Targeting Networking Technology (TTNT) waveform. It is expected that the vast majority of future test efforts will be focused around the QNT terminal.

\section{References}

[1] White, B.E. "Tactical data links, air traffic management, and software programmable radios." Proceedings of the 18th IEEE Digital Avionics Systems Conference, vol. 1, pp. 5.C.5-1 - 5.C.5-8, November 1999. 
[2] "MIDS FDL: Fighter Data Link (LVT

3)." www.rockwellcollins.com/ecat/gs/MIDS FDL. $\underline{\mathrm{html} \# \mathrm{~N} 12805}$

[3] Block, F.J. “Comparison of Jamming

Robustness of Airborne Networking Waveforms."

Proceedings of the 24 th IEEE Military

Communications Conference, vol. 4, pp. 2119

2125, October 2005.

[4] CJCSM 6120.01D, Joint Multi-Tactical Data

Link (TDL) Operating Procedures, November 2005.

[5] MIL-STD-6016C, Tactical Data Link (TDL) 16

Message Standard, March 2005.

[6] "FalconView Homepage."

www.falconview.org/overview.htm.

[7] CJCSI 6232.01D, Link-16 Spectrum

Deconfliction, December 2006.

[8] JTIDS/MIDS Spectrum Manager's Guide, version 1.1, April 2000.

[9] "Trident Warrior Website."

www.forcenet.navy.mil/tw/index.htm.

[10] "Anti-Surface Warfare Improvement

Program." www.ncts.navy.mil/homepages

/vp9/anti surface warfare improvement.htm

[11] "Office of Force Transformation: Network Centric Warfare Education Home Page."

www.oft.osd.mil/initiatives/stiletto/.
[12] Proof of Concept System Security

Authorization Agreement (SSAA) for Trident

Warrior 2007 MAX Link-16, version 1.0,

September 2006.

[13] "TADIL-J Host Simulator."

gateway.spawar.navy.mil/TJHS.html

\section{Acknowledgements}

The AFRL's Weapon Data Link Team would like to acknowledge several organizations including NETWARCOM, NCTSI Det 2, 552 ${ }^{\text {nd }}$ OSS, NSWC Carderock, OSD/OFT, NAS Patuxent River organizations, Navy JTIDS/MIDS NDF, Air Force JTIDS/MIDS NDF, CCSG-10, CVW-3, SPAWAR Norfolk, NMSC, Mid-Atlantic Frequency Coordination Office, and the DoD Gulf Area Frequency Office. A special acknowledgement goes to the MAX team from Rockwell-Collins for providing the technical support that made this demonstration possible.

\section{Disclaimer}

This work was supported by the Department of the Air Force under Contract No. F 33615-03-C1461. Opinions, interpretations, conclusions, and recommendations are those of the author and are not necessarily endorsed by the United States Government.

26th Digital Avionics Systems Conference

October 21, 2007 